\title{
Многофононная релаксация состояний двойных доноров серы и селена в кремнии

\author{
Бекин Н.А.
}

ИФМ РАН, 603950, Нижний Новгород, ГСП-105

DOI 10.34077/Semicond2019-317

Работа посвящена теоретическим оценкам вероятности многофононной релаксации в двойных донорах серы, S, и селена, Se. Рассматривается случай как нейтральных, так и однократно ионизованных доноров. Для расчетов используются простые модельные представления, игнорирующие многодолинный характер волновых функций. Таким образом, речь идет о получении грубых качественных оценок, исходя, главным образом, из энергетического зазора между вовлеченными в переход состояниями и локализации их волновых функций. Кроме того, для нейтральных доноров $\mathrm{S}^{0}$ и $\mathrm{Se}^{0}$ используется одноэлектронное приближение. А именно, используется модельное представление, что один из двух локализованных на доноре электронов находится на глубокой орбите, частично экранируя заряд иона. Таким образом, движение второго электрона, совершающего безызлучательные переходы, рассматривается в поле однократно заряженного остова. Для основного состояния нейтрального донора также использовалась одноэлектронная волновая функция, хотя это грубое приближение.

Рассматривается переход между триплетным уровнем $1 \mathrm{~s}\left(\mathrm{~T}_{2}\right)$ и основным состоянием $1 \mathrm{~s}\left(\mathrm{~A}_{1}\right)$. Для расчетов волновых функций обоих уровней использовался метод квантового дефекта, а вид волновой функции соответствовал симметрии $1 \mathrm{~s}$ водородоподобного центра $\mathrm{c}$ изотропной эффективной массой. Вероятности переходов рассчитывались в адиабатическом приближении. Использовался приближенный метод суммирования вкладов в вероятность перехода с учетом дисперсии фононов [1]. Предполагалось, что релаксация происходит при испускании оптических фононов одного типа - LO или ТО. Закон дисперсии фононов считался изотропным параболическим, $\omega(q)=\omega_{\max }\left(1-q^{2} / q_{0}^{2}\right)$, где $\hbar \omega_{\max }=64$ мэВ, величина $q_{0}$ выбиралась из условия, что минимальная частота, достигаемая на границе зоны Бриллюэна, соответствует частоте LO- или TO-фононов в точке X зоны Бриллюэна [2]. Зона Бриллюэна предполагалась сферически симметричной. Значение деформационного потенциала, $D=2.6 \cdot 10^{8}$ эВ/см, выбрано для всех доноров путем подгонки к экспериментальным данным по времени жизни уровня $1 \mathrm{~s}\left(\mathrm{~T}_{2}\right)$ в $\mathrm{Se}^{+}: \tau \approx 5.5$ нс [3]. Такая процедура подгонки эквивалентна введению усредненной по зоне Бриллюэна константы электрон-фононной связи, приближенно учитывая сильную локализацию вовлеченных в переход состояний.

Таблицุа 1. Темп многофононной релаксацчии

\begin{tabular}{|c|c|c|c|c|c|c|}
\hline & \multicolumn{2}{|c|}{ Энергия связи, мэB } & \multicolumn{2}{c|}{ LO } & \multicolumn{2}{c|}{ TO } \\
\cline { 2 - 8 } & $1 s\left(A_{1}\right)$ & $1 s\left(T_{2}\right)$ & $v, c^{-1}$ & $S_{H R}$ & $v, c^{-1}$ & 0.31 \\
\hline$S^{0}$ & 318 & 35 & $1.6 \cdot 10^{10}$ & 0.35 & $1.7 \cdot 10^{10}$ & 0.29 \\
\hline$S^{+}$ & 612 & 184 & $2.2 \cdot 10^{8}$ & 0.33 & $2.4 \cdot 10^{8}$ & 0.29 \\
\hline$S e^{0}$ & 307 & 35 & $2 \cdot 10^{10}$ & 0.32 & $2 \cdot 10^{10}$ & 0.29 \\
\hline$S e^{+}$ & 589 & 161 & $1.8 \cdot 10^{8}$ & 0.33 & $2 \cdot 10^{8}$ & 0 \\
\hline
\end{tabular}

В таблице 1 приведены энергии уровней доноров [2] и результаты расчетов - темп релаксации, v, и фактор Хуанга - Риса, $\mathrm{S}_{\mathrm{HR}}$.

Работа поддержана в рамках совместного российско-германского проекта РФФИ-ННИО (№. 389056032 и 18-502-12077-ННИО).

[1] D. Goguenheim, M. Lannoo, J. Appl. Phys., 68, 1059 (1990).

[2] A. Dargys, J. Kundrotas, Handbook on physical properties of Ge, Si, GaAs and InP, Vilnius (1994).

[3] K. J. Morse et al., Sci. Adv. 3, el700930 (2017). 